\title{
THE PROGRESS OF INBREEDING IN BARLEY
}

\author{
A. J. BATEMAN and K. MATHER \\ John Innes Horticultural Institution, Bayfordbury, Herts., and \\ Department of Genetics, University of Birminghom
}

\section{INTRODUCTION}

Received 26.ii.5I

THE genetical effect of inbreeding is to lower, generation by generation, the probability of an individual being heterozygous for any given gene, and correspondingly to raise the probability of it being homozygous for one or other allelomorph. Starting with a single individual, or a group of genetically like individuals (as in the $F_{1}$ of a cross between two true breeding strains), the chance of homozygosis for any gene which was initially heterozygous, can be calculated for any generation and any system of mating, on the supposition of mendelian inheritance. With $n$ generations of continuous self-fertilisation, the probability of homozygosis will be $\mathrm{I}-\left(\frac{1}{2}\right)^{n-1}$ as Mendel himself showed. The series for brother-sister mating was given by. Jennings (I9I6), and the consequences of other systems of mating have been worked out, not only for genes showing simple mendelian behaviour, but also where inheritance is complicated by linkage or polysomy (Haldane and Waddington, I93 I Bartlett and Haldane, I934; Fisher, I949).

It is, however, clear that the rise of homozygosis under any mating system will be profoundly affected by any selection, whether natural or artificial, which may be acting within the progenies. If heterozygotes should be favoured the rise of homozygosis will be slowed down, and in the extreme case may even be prevented. Similarly where homozygotes enjoy an advantage, homozygosis will be brought about with greater speed. Calculations based on the assumption of inheritance uncomplicated by selection can lead to expectations applicable only where selection is, in fact, absent ; and the validity of this assumption has become increasingly suspect in many of the species of plants and animals which have been inbred for experimental or for commercial purposes (e.g. Düzgünes, 1950).

Where a species normally reproduces by out-breeding it is commonly observed that individuals, which as a result of enforced inbreeding are heterozygous for fewer genes than usual, are also less vigorous than usual. Thus, the more heterozygous individuals will be expected to have an average advantage over their less heterozygous fellows, so that any competition, before seed-shedding or birth as well as in later life, may be expected to slow down the rise of homozygosis. Corresponding differences in fertility must aggravate this situation where the offspring of different individuals are allowed to compete with one another. 
With species which normally inbreed, such as barley, differences in vigour and fertility between outbred and inbred individuals are much smaller, though they often exist. Competition will, therefore, be expected to be less decisively in favour of the more heterozygous individuals, so that the rise of homozygosis under inbreeding following crossing will depart less, if at all, from simple expectation.

It may thus be anticipated that the rise of homozygosis under inbreeding will vary from species to species, according to the natural breeding systems. Certainly, calculations based on uncomplicated inheritance cannot adequately represent the situation. Experiments are needed from which can be estimated the speed with which homozygosis is attained.

\section{THE ESTIMATION OF PROGRESS UNDER INBREEDING}

Where the individual (or individuals) with which the inbreeding programme commenced, was heterozygous for one or more genes of major effect, the progress of inbreeding can be followed by recording the proportions of individuals detectable as homozygous for one or other allelomorph by direct observation or by a simple breeding test. It is obvious that genes whose differences themselves affect the breeding system will be unreliable as indicators, and in any case the estimates obtained by this method will be representative only so far as the effect of the indicator gene on the vigour and fertility of homozygotes and heterozygotes is representative of all the genes that are segregating. Now genes having a drastic effect on the phenotype commonly produce marked disturbances in vigour and fertility. Indicator genes must, therefore, be chosen with care if the results they give are to be accepted as reliable. Major genes suited to the purpose may not, in fact, be available in a species, or at least in the strain or strains whose behaviour under inbreeding it is desired to investigate.

A more generally applicable method for the study of departure of the progress of inbreeding from simple expectation is afforded by the biometrical analysis of continuous variation. Except in long inbred or specially prepared experimental stocks, there will be found heterozygosity and segregation of the members of the polygenic systems mediating continuous variation. Any measure of the rise of homozygosis to which they lead will be an average obtained from a number of genes, and will thus be more generally representative than that afforded by any but a most fortunately chosen single gene.

The biometrical method described by Mather (I949a and $b$ ) can be adapted for the purpose of following the progress of inbreeding. Starting with a single individual, or set of genetically uniform individuals, and assuming the scale upon which the expression of the character is measured to be appropriately chosen as eliminating or at least minimising genic interaction, the variation can be divided into three components, viz. (i) that depending on differences between 
comparable homozygotes and denoted by $D$, (ii) that depending on dominance of the genes and denoted by $H$, and (iii) that depending on non-heritable agencies and denoted by $E$. The different second degree statistics (variances and co-variances) which can be calculated from the various generations in a suitably designed experiment, can be expressed in terms of $D, H$ and $E$; and their observed relations can be compared with those expected on the supposition of uncomplicated inheritance under the mating system in force.

Thus the variance of an $\mathrm{F}_{2}$ can be expressed as $\frac{1}{2} D+\frac{1}{4} H+E_{1}$. The $F_{3}$ generation, raised by the self-fertilisation which occurs naturally in barley, yields three second degree statistics, the mean variance of families which is $\frac{1}{4} D+\frac{1}{8} H+E_{1}$, the variance of family means which is $\frac{1}{2} D+\frac{1}{16} H+E_{2}$, and the co-variance of $\mathrm{F}_{3}$ family mean with $\mathrm{F}_{2}$ parental value which is $\frac{1}{2} D+\frac{1}{8} H$. It will be observed that the $E$ component of the variance of family means is denoted by $E_{2}$ to distinguish it from $E_{1}$, occurring in the variance of $\mathrm{F}_{2}$ and mean variance of $\mathrm{F}_{3}$ 's. This is necessary because the non-heritable variation of a mean will differ from, and generally be less than, that of single individuals. The co-variance will, of course, have no non-heritable component in a properly designed experiment.

The $\mathrm{F}_{4}$ generation can yield five second degree statistics, since we can recognise not merely different families as the offspring of single $\mathrm{F}_{\mathbf{3}}$ individuals, but also different groups of families as the descendants of single $F_{2}$ individuals. The complexity of classification and the multiplicity of statistics increases correspondingly as we move on to $\mathrm{F}_{5}$ and later generations.

The barley experiment to be described was conducted (see Section 3) in such a way that only five statistics could usefully be found in each generation even after $\mathrm{F}_{4}$, viz. :-

(I) The mean variance of families.

(2) The variance of line means, which is the equivalent of the variance of group means in $\mathrm{F}_{\mathbf{4}}$.

(3) The variance of family means within lines (and averaged over lines), which is composite after $\mathrm{F}_{4}$.

(4) The co-variance of parental and offspring line means, which is the counterpart of (2), and

(5) The co-variance of parent value and mean of offspring within lines (and averaged over lines) which is the counterpart of $(3)$.

The expressions for these statistics are given in table $\mathrm{I}$. In $\mathrm{F}_{\mathbf{3}}$ of course, statistics (3) and (5) are not computable.

The heritable components of the variances can be added in each generation to give an expression for the total free variation. It will be observed that when this is done, the coefficient of $D$ follows Mendel's series for the chance of an individual of that generation being homozygous for one or other allelomorph of a gene heterozygous in the $F_{1}$. 


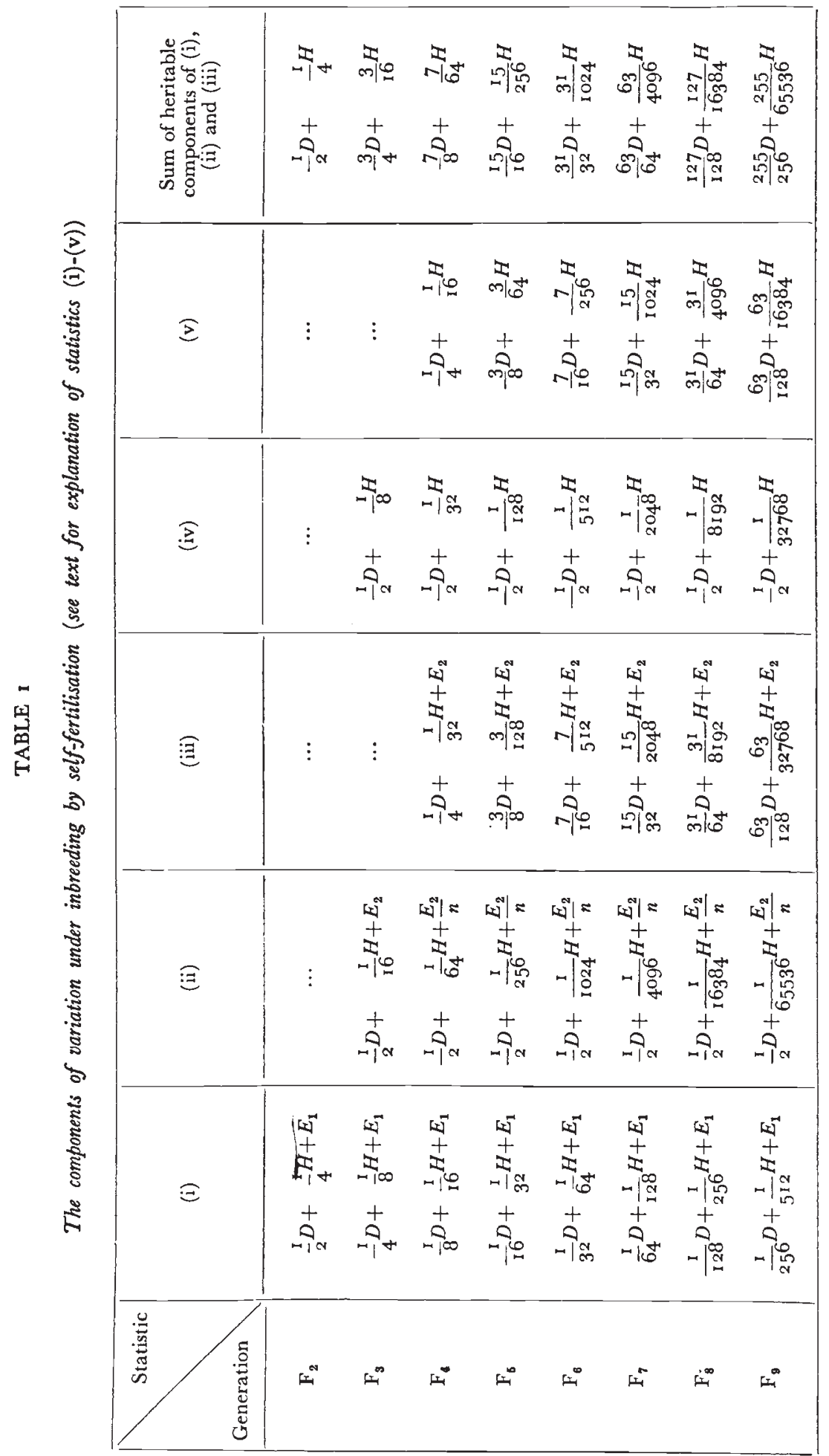


The coefficient of $D$ in generation $\mathrm{F}_{n}$ is $\mathrm{I}-\left(\frac{1}{2}\right)^{n-1}$, while the coefficient of $H$ approaches $\left(\frac{1}{2}\right)^{n-1}$ as $n$ becomes large. It is, however, always less than $\left(\frac{1}{2}\right)^{n-1}$ by an amount $\left(\frac{1}{2}\right)^{2(n-1)}$, thereby suggesting that the measure of total free heritable variability is omitting an item of size $\left(\frac{1}{2}\right)^{2(n-1)}$. This item is, in fact, represented by the departure of the mean measurement of the whole generation from the mid-parent value, i.e. from the mean of the measurements of the two true-breeding parental strains by crossing which the $F_{1}$ was produced or could have been produced. In Mather's notation the mean of $\mathrm{F}_{1}$ departs from the mid-parent by $\mathrm{S}(h)$ where $h$ is the departure caused by heterozygosity for a given gene from the mean of the two corresponding homozygotes. The departure of the $\mathrm{F}_{2}$ mean from the mid-parent is $\frac{1}{2} \mathrm{~S}(h)$, that of $\mathrm{F}_{3}$ is $\frac{1}{4} \mathrm{~S}(h)$ and that of $\mathrm{F}_{n}$ is $\left(\frac{1}{2}\right)^{n-1} \mathrm{~S}(h)$. Now $H$ is compounded of quadratic terms in $h$. Squaring the coefficient of $\mathrm{S}(h)$ in a corresponding way gives, for $\mathrm{F}_{n},\left(\frac{1}{2}\right)^{2(n-1)}$ which is the item required to complete the balance sheet of variability. When it is included, the coefficients of $D, H$ and $\mathrm{S}(h)$ sum to I. The free heritable variability is accounted for completely by reference to the three alternative states in which it can exist and which we regard as contributing to $D, H$ and $\mathrm{S}(h)$ respectively (Mather, 1949b).

Where the inbreeding programme commences with a single individual or a uniform $F_{1}$, produced by crossing two true-breeding strains, the total heritable variability as measured in this way will be constant over the generations in the absence of selection, provided that the genes are unlinked. The effect of linkage is to change the values of $D$ and $H$ from generation to generation. With preponderantly coupling linkage, $D$ declines in value as the generations proceed. With reinforcing dominance, $H$ declines in the same way. Preponderantly repulsion linkage and opposing dominance lead to $D$ and $H$ respectively increasing in value with the generations (Mather, I $949 a)$.

The distribution of variability, though not of necessity its total, will also be affected by selection, the precise effect depending on the nature of the selection itself. Where one allelomorph of the gene is favoured at the expense of the other, the values of $D$ and $H$ change (Mather, I949a); but where the effect is that of favouring heterozygosity as opposed to homozygosity, or vice versa, the consequence will be seen in the coefficients of $D$ and $H$. With heterozygosity favoured, the coefficients of $D$ will be lower than those expected, and those of $H$ higher by amounts which increase progressively with the generations. With homozygosity favoured, the departures will go in the opposite direction. In the extreme case where only the individuals heterozygous for all genes contribute to the next generation, the coefficients of $D$ and $H$ will remain at $\frac{1}{2}$ and $\frac{1}{4}$ respectively instead of changing with the series $1-\left(\frac{1}{2}\right)^{n-1}$ and $\frac{1}{2}^{n-1}\left(1-\frac{1}{2}^{n-1}\right)$. At the other extreme where only the various homozygotes breed, the coefficient of $D$ will be I and that of $H$ will be $\mathrm{o}$ in every generation after $\mathrm{F}_{2}$. These extremes have, 
however, little more than academic interest, for we can expect to meet them rarely, if ever.

Thus, in theory, linkage and selection have separable effects, on the values and coefficients of $D$ and $H$ respectively (figs. I and 2). In practice they will be more difficult to distinguish. When we analyse data we shall find that the effects of both linkage and selection will appear as changes from generation to generation in the values of $D$ and $H$ if these are permitted to vary, or in their coefficients if they are not. Doubtless some separation of their effects is possible by suitable analysis, but this has yet to be attempted. For the present it is sufficient to note that where homozygotes are favoured the result will resemble (at least superficially) that of coupling linkage, and where heterozygotes are favoured the result will resemble that of repulsion linkage, figs. 3 and 4 .

One point remains to be noted before we turn to the experimental results obtained with barley. This cereal naturally self-pollinates, and our discussion of the use of the biometrical method in the study of inbreeding has, therefore, been based on the assumption of this breeding system. The consequences of other breeding systems, leading for example to brother-sister or cousin mating, can, however, be represented by reference to $D$ and $H$ in the same way. It is the properties of our experimental material that leads us to discuss inbreeding in terms of self-pollination : the method of analysis is in essence a general one.

\section{THE EXPERIMENT}

The experiment began as far back as 1938 , with a cross between the two barley varieties, Spratt and Irish Goldthorpe. The cross was made for the production of large $\mathrm{F}_{2}$ and $\mathrm{F}_{3}$ families for the biometric analysis of $D$ and $H$ published elsewhere (Mather and Philip-see Mather, 1949a). All the plants used for that analysis were grown in $\mathrm{I}_{94} \mathrm{I}$. In that year some of the ears on five $\mathrm{F}_{2}(A)$ plants and two $\mathrm{F}_{3}(B)$ plants were bagged and some ears were left unbagged. These seven plants were the source of all the later generations dealt with in this paper, each giving rise to one of the seven lines. Twenty seeds from the bagged ears and twenty from the unbagged ears were sown in a randomised block in 1942 , producing 14 families. The progenies of bagged and unbagged ears formed duplicate series designated $b$ and $u$.

Ears were bagged on one or two plants in each family in 1942. These plants produced $20 b$ and $20 u$ families in 1943. From 1942 to r 945 inclusive all the families were grown together in a single randomised block. Each r 943 family had $b$ and $u$ seed saved from one or two plants in such a way that every 1942 family was represented in 1944 by 8 families ( $4 u$ and $4 b$ ), making $\mathrm{I}$ I 2 families in all, each of ro plants. The method of producing two families from one plant in each family of the previous generation had doubled the number 


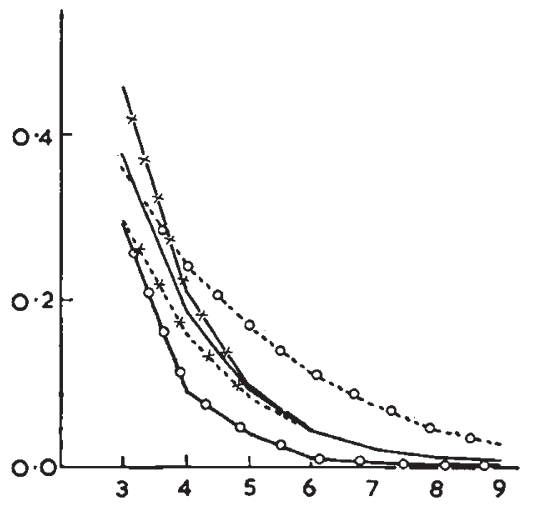

Fig. 1.-Mean Variance.

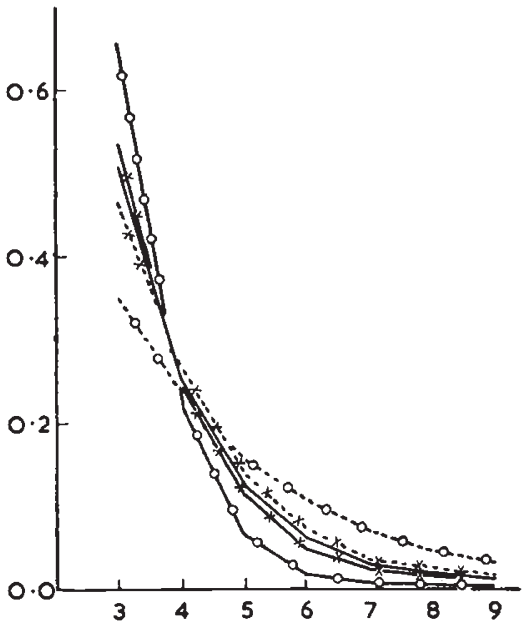

Fig. 3.-Mean Variance.

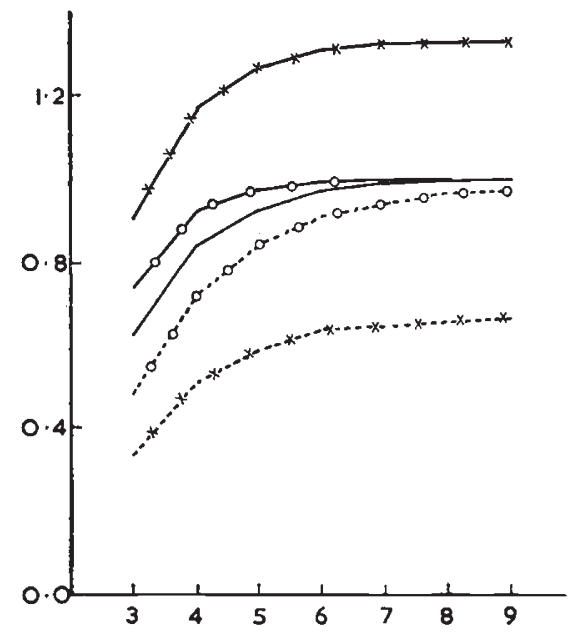

FIG. 2.-Covariance of Parent and Progeny.

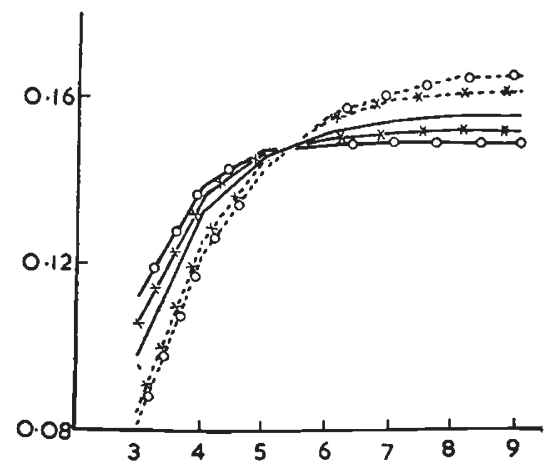

Fig. 4.-Covariance of Parent and Progeny.

General legend to figs. $1-4$

The effects of linkage and selection on Mean Variance and Parent-offspring Covariance from $F_{3}$ to $F_{8}$.

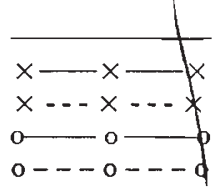

Simple inheritance.

Linkage in coupling.

Linkage in repulsion.

Selection favouring homozygotes.

Selection favouring heterozygotes.

There are assumed to be two genes $A-a$ and $B-b$ of equal effect with a linkage value (when linked) of 0.25 and a selection ratio (when effective) of $2: 1$. In figs. 1 and 2, $d_{a}=d_{b}=h_{a}=h_{b}=\sqrt{\frac{1}{2}}$, and the general levels of Mean Variance and Covariance over the generations vary with the linkage and selection. In practice, however, the general levels of these statistics are given and it is the changes from generation to generation with which we are concerned. In figs. 3 and 4 , therefore, whilst $d_{a}=d_{b}=h_{a}=h_{b}$, their values vary in such a way that the sum of the statistics from $F_{3}$ to $F_{0}$ is constant at unity.

In figs. 3 and 4 the linkage curves deviate from simple inheritance less than the selection curves. With more linked genes, however, the deviation would be increased. 
of families in each generation. In 1944 the multiplication of lines was halted. From then on only half the families of one generation were represented by two families in the next, the other half being unrepresented, so stabilising the number of families.

The comparison of the $u$ and $b$ series had been designed to detect the origin of new variation by outcrossing. No difference between the two series had been observed up to 1944. Furthermore, outcrossing in this barley material seemed most unlikely on botanical grounds, for anthesis invariably preceded the emergence of the ear from its sheathing leaf.

Insistence on the recovery of $u$ and $b$ seed from every parent plant sometimes meant losing a line because the bagged ear had broken off. It also meant that parent plants had to have a minimum of two ears. Consequently in view of th: $:$ pparent absence of outcrossing, no ears were bagged from 19450 : vards. Replication was maintained by dividing the seed from each parent plant into two equal lots $x$ and $y$ which were sown in two randomised blocks $X$ and $Y$. A further break in the uniformity of treatment in the experiment was inadvertently made in 1946 . In this year alone the practice of obtaining the replicate families ( $u$ and $b$ or $x$ and $y$ ) from a single parent plant was dropped. Instead, the $x$ and $y$ replications were obtained from plants in the $X$ and $Y$ blocks respectively. In 1947 therefore, the non-heritable variation between $x$ and $y$ was confounded with the sampling variance of the parents. As will be seen fron fig. $3 \mathrm{~A}$ this did not appear to inflate unduly the estimate of $E_{2}$. Nor vould it be expected to do so, since the heritable variation within families should be small by this time. The pedigrees of the experiment is summarised in fig. 5 .

The experimental blocks consisted of rows one foot apart with the seeds hand-sown singly at six inches apart. A modification of this was made in 1947 and 1948 in order to reduce the error engendered in the statistics by families containing markedly fewer than the maximum of ten mature plants. The seeds were sown in pairs one inch apart at right angles to the rows. When germination had been completed the seedlings were singled. This improved the stand at harvest though it was still incomplete.

Since the analysis of the experiments is based on a comparison between generations it is important that each family in one generation be represented equally in the next generation. Otherwise the comparison between generations is of doubtful value. For this reason, as has been stated above, each I94I parent plant was represented by I 6 families in 1944. After 1944, however, a number of family sequencies died out. In order to maintain the balance double weight was given to the most closely related family, in calculating the statistics. If the families were lost at random this would be the best treatment. The analysis of the data which follows gives, however, good cause to suspect the action of selective loss of families. Statistics obtained by the system of weighting adopted would tend to mask the action of 
selection. They have therefore been recalculated, giving equal weight to all surviving families at each generation.

The previous analysis of barley data (loc. cit.) was carried out on a discriminant function involving ear length, ear breadth and the length

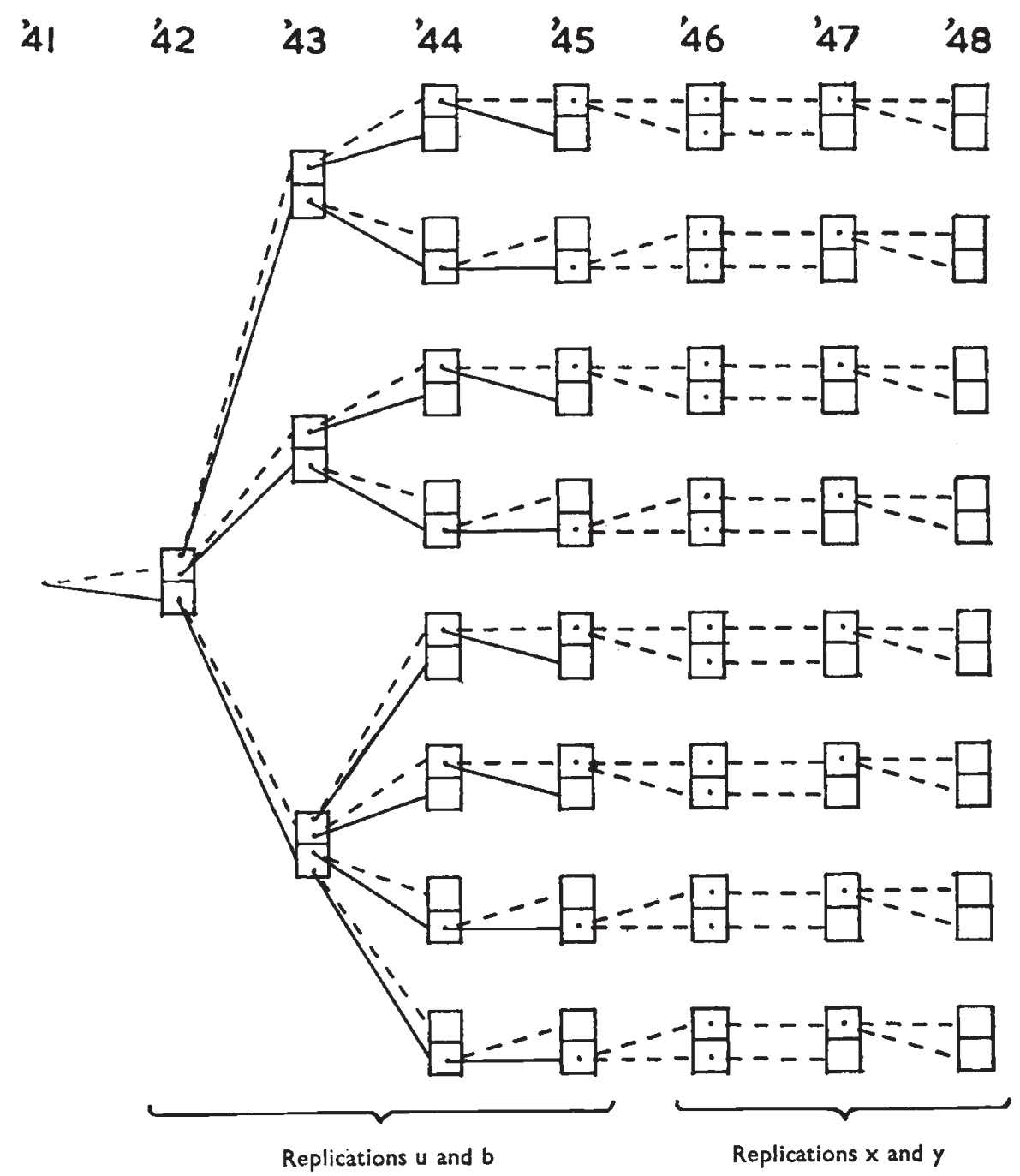

FrG. 5. - The pedigree of all the families within one line, i.e. descended from a single $194^{\mathrm{I}}$ plant. Each square represents a family ; each dot within a square, a parent plant. Entire lines, descent via a bagged ear ; broken lines, by an unbagged ear. The paired squares represent replicates from which the duplicate statistics were obtained. For further details see text.

of the middle twelve internodes (the length taken up by seven nodes on one side of an ear). Since the greatest weight was given to internode length it has been thought sufficient to take the internode length alone in the following analysis, thus saving a great deal of labour. 
Fourteen internodes were measured from the first. When it was discovered that the earlier discriminant had been based on twelve internodes, it was thought not worth while altering the metric. One ear taken at random was used to represent each plant. The measurements were all expressed in millimetres.

In so far as we are concerned to see the effects of selection on the barley statistics, it is appropriate to consider the opportunities it might have had of influencing the results of the experiment.

The choice of the parent of the next generation from each family was as far as possible genetically random. The fifth plant in the row of ten, or what would have been fifth if all ten plants had matured, was taken if it produced a minimum of two ears at time of bagging (for $u, b$ series), or a minimum of one mature ear at time of harvesting (for $x, y$ series). Failing this the nearest suitable plant to it was taken. In only a small minority of families was the fifth plant unsuitable as a parent (no record was kept of the proportion). Nevertheless, as can be seen from table 2, in every generation the mean of the plants

TABLE 2

Comparison of mean of parents with mean of families from which they came and mean of their progeny (families of following year)

\begin{tabular}{|c|c|c|c|c|c|c|c|c|}
\hline Year & Parent & Family & $\begin{array}{c}\text { Parent- } \\
\text { Family }\end{array}$ & $\begin{array}{l}\text { Parent- } \\
\text { Progeny }\end{array}$ & Line & Parent & Family & $\begin{array}{l}\text { Parent- } \\
\text { Family }\end{array}$ \\
\hline $\begin{array}{l}1941 \\
1942 \\
1943 \\
1944 \\
1945 \\
1946 \\
1947 \\
1948\end{array}$ & $\begin{array}{c}36 \cdot 43 \\
36 \cdot \mathrm{I} I \\
35 \cdot 87 \\
34 \cdot 85 \\
35 \cdot 99 \\
38 \cdot 26 \\
39 \cdot 57 \\
\ldots\end{array}$ & $\begin{array}{l}35 \cdot 67 \\
35 \cdot 67 \\
34 \cdot 49 \\
33 \cdot 51 \\
37 \cdot 56 \\
38 \cdot 80 \\
3^{8} \cdot 07\end{array}$ & $\begin{array}{c}\ldots \\
o \cdot 44 \\
o \cdot 20 \\
o \cdot 36 \\
2 \cdot 48 \\
o \cdot 70 \\
o \cdot 77 \\
\ldots\end{array}$ & $\begin{array}{c}o .76 \\
o .44 \\
I .38 \\
I .34 \\
-1.57 \\
-0.54 \\
r .50 \\
\ldots\end{array}$ & $\begin{array}{ll}\text { A } & 4 \\
\text { A } & 5 \\
\text { A } & 8 \\
\text { A } & 9 \\
\text { A } 10 \\
\text { B } & \text { I } \\
\text { B } & 5\end{array}$ & $\begin{array}{c}25 \cdot 38 \\
31 \cdot 66 \\
47 \cdot 28 \\
32 \cdot 66 \\
46 \cdot 56 \\
30 \cdot 32 \\
43 \cdot 56 \\
\ldots\end{array}$ & $\begin{array}{c}24 \cdot 98 \\
30 \cdot 5 \mathrm{I} \\
45 \cdot 59 \\
32 \cdot 25 \\
44 \cdot 4 \mathrm{I} \\
3 \mathrm{I} \cdot 20 \\
4^{2} \cdot 7 \mathrm{I} \\
\ldots\end{array}$ & $\begin{array}{r}0.40 \\
I .16 \\
I .69 \\
o .4 I \\
2.15 \\
-0.88 \\
0.85 \\
\ldots\end{array}$ \\
\hline \multicolumn{3}{|c|}{$\begin{array}{l}\text { Mean Difference } \\
\text { Probability }\end{array}$} & $\begin{array}{l}0.825 \\
0.05\end{array}$ & $\begin{array}{l}o \cdot 473 \\
o \cdot 3\end{array}$ & & & & $\begin{array}{l}0.826 \\
0.05\end{array}$ \\
\hline
\end{tabular}

used as parents was greater than that of the families from which they were drawn. That this excess was not confined to certain constitutions is shown by the same comparison analysed by lines (each line is, it will be recalled, descended from a single 194 I plant) instead of generations. In both cases the excess of the parental means just reaches the 5 per cent. level of significance. In the comparisons according to lines there is evidence that the excess increases with the mean.

That the excess of the parent plants is partly non-heritable is shown in the parent-progeny comparison (the difference between parent mean of one year and family of the next). Here the error variance is naturally higher, since the comparison involves the different 
environments of the two years. The mean difference is still positive, however, but it is smaller and has no statistical significance.

Some measure of the scope for selection is given by the variation in fertility and survival rate. If all families gave a complete stand of mature plants there would be no opportunity for selection except at the gametic level. This was far from the case. Table 3 shows the variation in fertility expressed as number of mature plants obtained out of a maximum possible of $\mathrm{I} 0$. In the years up to 1947 the deficiency stems from four causes: failure of the parent to give sufficient seeds for complete sowing; poor germination of the seed ; post-seedling death of the plant and failure of the plant to produce ears. In 1947 and 1948 , as will be remembered, two seeds were sown for every one plant required. This reduces the effect of poor germination but the other factors are unaffected. The variation between lines in fertility as shown in table 3 is highly significant

TABLE 3

Fertility as measured by number of plants surviving out of the ten required

\begin{tabular}{|c|c|c|c|c|c|c|c|c|}
\hline Year & 1942 & 1943 & r944 & x945 & x946 & I947 & $\times 948$ & Line Mean \\
\hline $\begin{array}{ll}\text { A } & 4 \\
\text { A } & 5 \\
\text { A } & 8 \\
\text { A } & 9 \\
\text { A } & \text { O } \\
\text { B } & \text { I } \\
\text { B } & 5\end{array}$ & $\begin{array}{r}10 \cdot 00 \\
9 \cdot 75 \\
10 \cdot 00 \\
6 \cdot 50 \\
9.00 \\
10 \cdot 00 \\
9.00\end{array}$ & $\begin{array}{l}8 \cdot 25 \\
9 \cdot 13 \\
9 \cdot 63 \\
9 \cdot 3^{8} \\
9 \cdot 50 \\
9 \cdot 13 \\
9 \cdot 5^{\circ}\end{array}$ & $\begin{array}{l}4 \cdot 3^{8} \\
7 \cdot 3^{6} \\
8 \cdot 00 \\
6 \cdot 75 \\
7 \cdot 19 \\
7 \cdot 13 \\
6 \cdot 88\end{array}$ & $\begin{array}{l}5 \cdot 88 \\
6 \cdot 34 \\
8 \cdot 00 \\
6 \cdot 94 \\
5 \cdot 08 \\
7 \cdot 00 \\
8 \cdot 08\end{array}$ & $\begin{array}{l}5 \cdot 13 \\
6 \cdot 88 \\
7 \cdot 93 \\
4 \cdot 72 \\
6 \cdot 30 \\
6 \cdot 88 \\
5 \cdot 93\end{array}$ & $\begin{array}{l}7 \cdot 57 \\
8 \cdot 38 \\
9 \cdot 43 \\
7 \cdot 23 \\
8 \cdot 63 \\
8 \cdot 75 \\
8 \cdot 50\end{array}$ & $\begin{array}{l}5 \cdot 13 \\
7.3^{8} \\
8 \cdot 43 \\
8 \cdot 43 \\
7.63 \\
6.63 \\
7.57\end{array}$ & $\begin{array}{l}6.62 \\
7.81 \\
8.77 \\
7 \cdot 14 \\
7.62 \\
7.93 \\
7.92\end{array}$ \\
\hline Yearly Mean & $9 \cdot 18$ & $9 \cdot 22$ & $6 \cdot 8 x$ & $6 \cdot 76$ & $6 \cdot 18$ & $8 \cdot 3^{6}$ & $7 \cdot 3^{x}$ & $\cdots$ \\
\hline
\end{tabular}

(probability oor). The variation from year to year is even greater. The variation between lines is mainly due to the high fertility of A8 (high mean internode length, 40-50 mm.) and low fertility of $\mathrm{A}_{4}$ (lowest length, around $25 \mathrm{~mm}$.) and A9 (moderately low length, around $30 \mathrm{~mm}$.). This is further evidence of selection against low values.

The year to year variation in fertility is mainly due to a steady fall from 1942 to 1946 . With the new sowing technique it rose markedly in 1947 and 1948 . Poor seed germination is thus an important factor in lowering fertility, though not the only one. The steady fall in the earlier generations is evidently connected with loss of vigour as a result of inbreeding. In this connection it is worth noting that evidence of heterosis in respect of the ear characters was obtained by Mather and Philip (r949a). The results could, however, be explained without reference to hybrid vigour. The two parental forms were internally very well balanced as a result of selection in the homozygous state. The balance might remain in the $\mathrm{F}_{\mathbf{1}}$ which 
would contain the two balanced systems side by side. On inbreeding, however, various homozygous combinations of the two parental gene systems would be produced and it would be surprising if these novel combinations were all well balanced. Such inbreeding depression is of a different order of magnitude from that obtained in outbreeding organisms like maize and Drosophila. The marked depression in maize, greater than that of the barley though it is, is even then obtained in material continuously subject to upward selection by man.

It may be asked why in $F_{3}$ and $F_{4}$ there is an almost complete stand, though these generations should show 0.75 and 0.875 homozygosity respectively. It must be borne in mind that we are here concerned not with vigour as such but ability to produce a complete stand of mature plants. It might well be that considerable reduction in vigour can occur before the threshold is passed which reduces the stand. Furthermore, two of the most important factors, number of seeds available for sowing and the germination rate, are largely maternally determined, that is, affected by the previous generation with twice the heterozygosity.

In only one year (1945) was a record kept of the number of grains harvested from the two ears of each parent plant. Only for that year, therefore, is it possible to obtain an idea of the relative importance of infertility of the parent and failure of seeds to produce mature plants. In I 945, of $4^{2}$ parent plants, I 3 produced less than the required number of seeds (twenty). As a result of the infertility of these parents the mean number of seeds sown per parent plant was $17 \cdot 26$. The mean number of plants harvested per parent was only $12 \cdot 50$. In this year the period from seed to mature plant was a more important field for the operation of natural selection than the fertility of the parents.

\section{ANALYSIS OF THE RESULTS}

\section{(i) Means}

The grand mean of the experiment shows little evidence of any general trend during the course of the experiments, though the means are higher during the years $1946-48$ than earlier. This could, of course, be due to seasonal effects.

When, however, the data are broken down so as to show the behaviour of each of the seven lines, complications become apparent (fig. 6). There is a clear tendency for the lines to diverge from one another, while keeping the same grand mean, at least up to 1945 . The overall change in mean from 1946 onwards makes interpretation of this later part of the experiment more difficult.

The interpretation to be placed on this divergency of the lines is not obvious. It will be seen from the figure that various families died out in the early years, but these show little evidence of being distributed in such a way as to cause the effect observed. It would seem that we must rather attribute the effect to differential survival within families ; 
and indeed our discussion of fertility has already shown ample scope for divergence to arise in this way.

The remarkable feature of the results is that such selection should give rise to divergence. This must mean that genotypes of intermediate effect were at a disadvantage, in spite of the fact that the two parents were actually of intermediate internode length. The parents were,

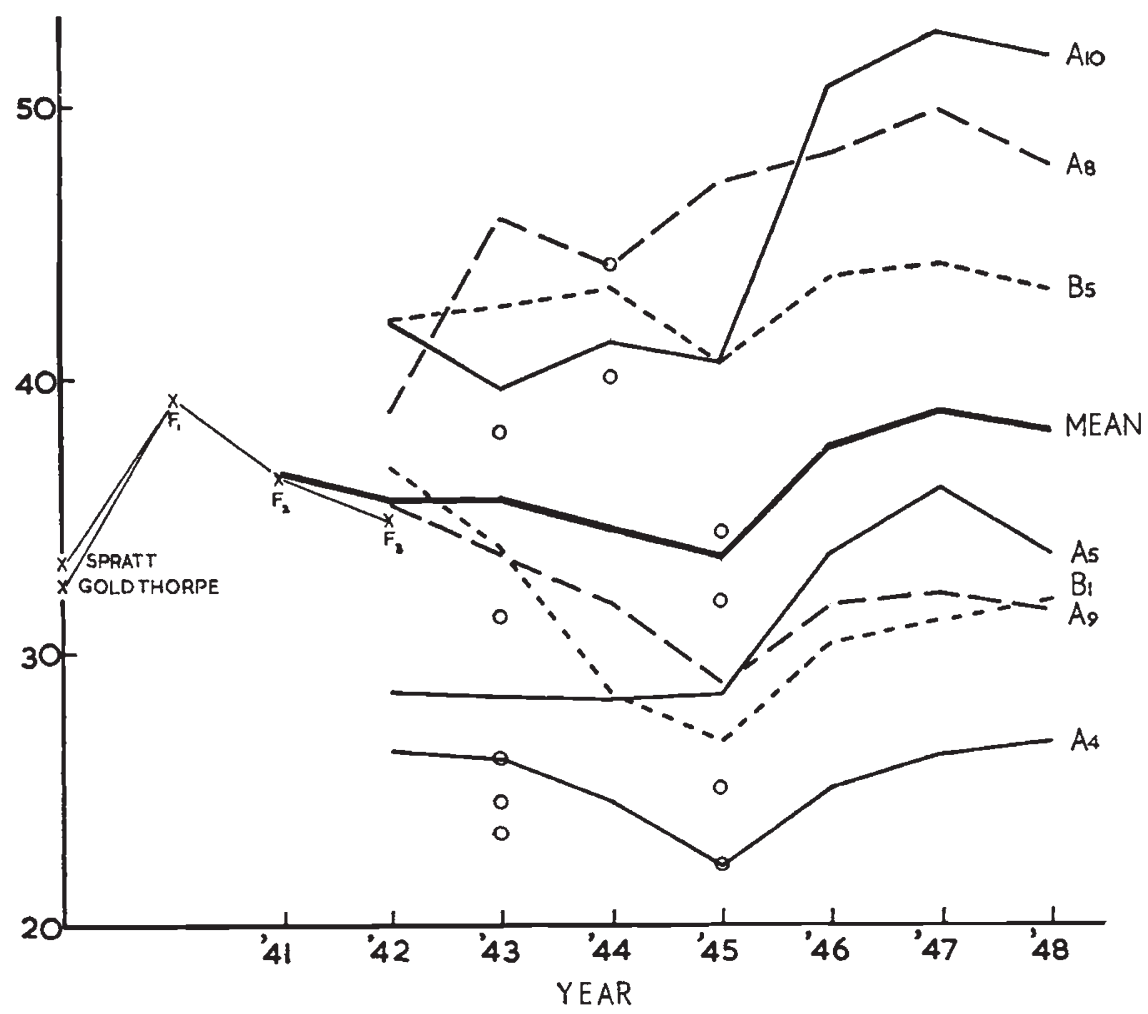

FIG. 6.-The generation to generation variation in the Grand Mean, ear measurement (thick black line), and in the 7 line means making up the Grand Mean. The thin line with the $X$ 's represents Mather and Philip's means for the corresponding generations which were, in fact, all grown in the same season (I94I). The circles show the means of families which failed to produce any offspring.

however, intermediate because of the balancing action of two groups of linked genes opposed in their effects in each parent (Mather, I949a). In the offspring of their cross further genotypes of intermediate effect would be expected from recombination in these linked groups, and it may well be that these genetically new intermediates are the ones against which selection has been acting, so bringing about the divergence. In fact, such an assumption implies that the genotypes produced by recombination within the linkage groups are at a disadvantage, as compared with those others of more extreme effect on the internode length arising by re-assortment of the unbroken 
groups. This is in keeping with observations on the course of selection in Drosophila (Mather and Harrison, 1949).

It is of interest in this connection that the present observations afford some confirmation of Mather, and Philip's view that the parents differed in two groups of linked genes opposed in their effects on internode length.

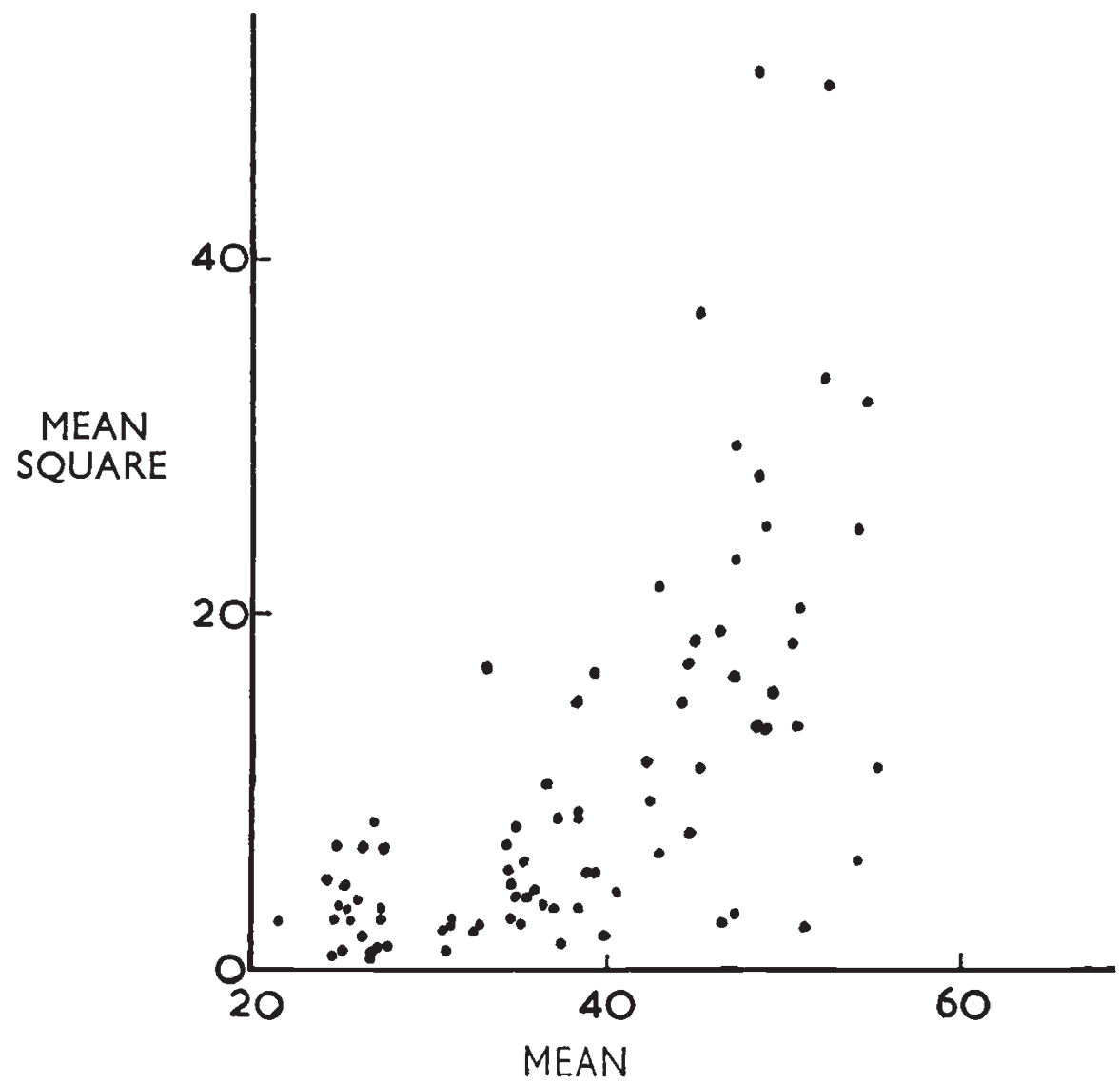

FIG. 7.-Comparison of Mean Square and Mean for all families grown in $1948\left(F_{9}\right)$. If the scaling were perfect there would be no relation between the two statistics, as there clearly is.

Such selection against intermediate phenotypes is not one of particular genes as such, but one of particular combinations of these genes. It need not, therefore, upset the individual gene frequencies, nor even the relative frequencies of homozygosis of the individual gene and indeed, the behaviour of the grand mean shows little evidence of such upset. It will, however, affect certain of the statistics, as we shall see later. No change of scale could compensate for its effects.

A further feature of the material which will have its effect on 
certain of the statistics could perhaps be overcome by rescaling. In I $94^{8}$, when the lines would be expected to have attained a high level of homozygosis, the means and variances of the various families were plotted against one another. The variances should be almost entirely non-heritable and, on a fully adequate scale, should be equal, or at least uncorrelated with the means, since they will reflect vagaries of the environment to which all families have an equal chance of being subjected. As fig. 7 shows, however, there is a clear positive correlation of family mean and variance, the variance rising, in fact, rather more quickly than the square of the mean. A logarithmic transformation might well remove this metrical bias, but it has not been attempted because of the great labour involved. In the case of the mean variance which is the statistic most affected by such bias, an approximate correction has been used, as will be explained when attention is turned to that statistic.

A final point remains to be made before turning to the analysis of the statistics. The experiment was conducted in such a way as to afford no direct means of estimating the non-heritable variation to which individual plants were subject $\left(E_{1}\right)$. The comparison of progenies from bagged and unbagged ears of the same plant, in the earlier years, and the comparison (after correcting for block differences) of the $x$ and $y$ duplicates in the later years affords a means of estimating the non-heritable variation of family means $\left(E_{2}\right)$. These statistics are set out line by line and year by year in table 4 . There is a decline

TABLE 4

Variation in $\mathrm{E}_{\mathbf{2}}$

\begin{tabular}{|c|c|c|c|c|c|c|c|c|}
\hline Year & $194^{2}$ & 2943 & 1944 & 1945 & 1946 & 1947 & $194^{8}$ & Line Mean \\
\hline $\begin{array}{ll}\text { A } & 4 \\
\text { A } & 5 \\
\text { A } & 8 \\
\text { A } & 9 \\
\text { Ar } \\
\text { B } & \text { I } \\
\text { B } & 5\end{array}$ & $\begin{array}{l}\ldots \\
\cdots \\
\cdots \\
\cdots \\
\cdots \\
\cdots \\
\cdots\end{array}$ & $\begin{array}{l}0 \cdot 69 \\
1.60 \\
8 \cdot 53 \\
I \cdot 73 \\
5 \cdot 01 \\
0 \cdot 62 \\
2 \cdot 82\end{array}$ & $\begin{array}{r}\mathrm{I} \cdot 40 \\
2 \cdot 46 \\
4.49 \\
\mathrm{I} \cdot 58 \\
\mathrm{I} \cdot 54 \\
\mathrm{I} \cdot 76 \\
\mathrm{I} 0 \cdot 16\end{array}$ & $\begin{array}{l}0.96 \\
2 \cdot 3 \mathrm{I} \\
7 \cdot \mathrm{I} \\
2 \cdot 0 \mathrm{I} \\
4 \cdot 65 \\
\mathrm{I} \cdot 07 \\
\mathrm{I} \cdot 95\end{array}$ & $\begin{array}{l}0 \cdot 43 \\
3 \cdot 68 \\
4 \cdot 73 \\
3 \cdot 30 \\
6 \cdot 15 \\
0 \cdot 45 \\
3 \cdot 74\end{array}$ & $\begin{array}{l}2 \cdot 29 \\
0.50 \\
1 \cdot 70 \\
8 \cdot 16 \\
3.01 \\
2.48 \\
0.85\end{array}$ & $\begin{array}{l}0.73 \\
1.65 \\
0 \cdot 80 \\
1.39 \\
0.58 \\
2 \cdot 28 \\
3.45\end{array}$ & $\begin{array}{l}x \cdot 08 \\
2 \cdot 03 \\
4 \cdot 56 \\
3 \cdot 03 \\
3.49 \\
1 \cdot 44 \\
3.83\end{array}$ \\
\hline Yearly Mean & $4 \cdot 6 \mathrm{I}$ & $3 \cdot 00$ & $3 \cdot 34$ & $2 \cdot 87$ & $3 \cdot 21$ & $2 \cdot 7^{x}$ & $x \cdot 56$ & ... \\
\hline
\end{tabular}

in 1947 and 1948 , as would indeed be expected from the precautions taken to ensure a better stand and so more plants per family in these later years. There is also a correlation of line $E_{2}$ with the line internode length, as would be expected from the relation of mean and variance already noted. These differences are, however, small when compared with the changes observed in the statistics as a result of the inbreeding. We may thus take it that $E_{2}$, and by inference $E_{1}$, 
are sufficiently near to being constant to cause us little trouble in analysis and interpretation of the experimental results.

\section{(ii) Second degree statistics}

Before turning to the analysis of the variances and covariances, two points require mention. The first concerns the group of lines designated by $B$. This originated from a single $\mathrm{F}_{3}$ family, i.e. from one $\mathrm{F}_{2}$ plant. For the purpose of analysis, therefore, we can regard this $F_{2}$ plant as corresponding to an $F_{1}$, the $F_{3}$ family to an $F_{2}$ and all the later generations to a generation one earlier than their formal place in the complete experiment would indicate. This course has been adopted in the analysis that follows. It may be noted in this connection that the series $B$, viewed in this way, originates from an $F_{1}$ plant which may have less, but cannot have more, genes heterozygous (and hence variability) than the original $F_{1}$ which gave rise both to it and, more directly, to the series of lines designated by $A$. Furthermore, any linkage the genes may show will not necessarily be the same in $B$ as in $A$.

Secondly, all the statistics (means, variances and covariances) in both series $A$ and $B$, were observed in duplicate. This was made possible by growing duplicate families from each parent (except in 1947). In such a system the differences between duplicates reflect sampling variation within families but not between parents. Since this latter sampling variation must have its effect on the changes of the statistics from generation to generation, and such sampling effects in parents must have been large especially in the early generations where few parents were used, the differences between duplicate observations will generally be too small to provide (except in 1947), an estimate of the error with which the changes among the statistics can fairly be compared. No use has, therefore, been made of these differences, and the means of the duplicate observations have been utilised throughout. The comparison in behaviour of $A$ and $B$ affords a general idea of the reliability of the results.

The $\mathrm{F}_{6}$ generation contained a number of families in the $A$ series which produced no $F_{7}$ progeny, the absence of which could not be made up by weighting as there were no close relatives to be weighted. For this reason two values are given for each statistic in $\mathrm{F}_{6}$ of series $A$, the one being strictly comparable with its counterparts from earlier generations and the other with those from later ones. The data seemed, however, not to warrant the extra labour of making these comparisons separately. An average was therefore taken of the two values of each statistic in $\mathrm{F}_{6}$ and these averages used in the consideration of the changes in $A$.

In the absence of selection the variance of $\mathrm{F}_{2}$ is expected to be $\frac{1}{2} D+\frac{1}{4} H+E_{1}$, where $E_{1}$ represents the non-heritable component of variation between individual plants. With simple inheritance, 
uncomplicated by linkage or selection, the heritable portion of the mean variance of families is halved in every generation, the mean variance of $\mathrm{F}_{3}\left(\overline{\mathrm{VF}}_{8}\right)$ being $\frac{1}{4} D+\frac{1}{8} H+E_{1}$ and so on. The $E_{1}$ item, of course, appears every time. Since no control families were used and the different generations were grown in different years and on different

TABLE 5

Mean variance (weighted data)

\begin{tabular}{|c|c|c|c|c|c|c|c|c|}
\hline \multirow{3}{*}{ Generation (F) } & \multicolumn{4}{|c|}{ Series $A$} & \multicolumn{4}{|c|}{ Series $B$} \\
\hline & \multicolumn{3}{|c|}{ Observed } & \multirow{2}{*}{ Expected } & \multicolumn{3}{|c|}{ Observed } & \multirow{2}{*}{ Expected } \\
\hline & \multicolumn{2}{|c|}{ Duplicates } & Mean & & \multicolumn{2}{|c|}{ Duplicates } & Mean & \\
\hline 3 & $20 \cdot 11$ & $29 \cdot 48$ & $24 \cdot 80$ & $22 \cdot 79$ & $29 \cdot 34$ & 24.71 & 27.03 & 24.09 \\
\hline 4 & $10 \cdot 70$ & 11.60 & Ix'15 & $15 \cdot 19$ & $8.4 \mathrm{I}$ & 7.67 & 8.04 & 15.23 \\
\hline & $9 \cdot 53$ & $14 \cdot 37$ & $x \times 95$ & $11 \cdot 39$ & $11 \cdot 06$ & $17 \cdot 77$ & $14.4 x$ & 10.80 \\
\hline $\begin{array}{l}6 \text { inclusive } \\
6 \text { exclusive }\end{array}$ & $7 \cdot 55$ & 8.82 & $8 \cdot 48$ & $9 \cdot 49$ & $5 \cdot 83$ & $4 \cdot 96$ & $5 \cdot 39$ & 8.58 \\
\hline 7 & $\begin{array}{l}0 \cdot 12 \\
6 \cdot 91\end{array}$ & $\begin{array}{l}940 \\
6.85\end{array}$ & 6.88 & & $8 \cdot 31$ & & $9 \cdot 26$ & $7 \cdot 48$ \\
\hline 8 & 8.02 & $11 \cdot 79$ & 9.90 & 8.07 & 7.67 & $7 \cdot 15$ & 7.41 & 6.93 \\
\hline 9 & $10 \cdot 06$ & $10 \cdot 19$ & 10.13 & $7 \cdot 93$ & $7 \cdot 76$ & $8 \cdot 63$ & $8 \cdot 20$ & 6.65 \\
\hline
\end{tabular}

plots of ground, there can be no certainty that $E_{\mathbf{1}}$ did not itself vary from generation to generation. It will be assumed, however, that $E_{1}$ was in fact constant. There is, as we have seen, some support to be obtained from the data for this assumption. It will be observed that $H$ declines proportionately with $D$ over the generations. There is therefore no need to discuss the effect of dominance as a separate consideration ; we require only estimates of $D+\frac{1}{2} H$ and of $E_{1}$. Using the method of least squares on the weighted data from $\mathrm{F}_{3}-\mathrm{F}_{9}$, these are $D+\frac{1}{2} H=60 \cdot 80$ and $E_{1}=7.59$ for $A$, and $D+\frac{1}{2} H=70.86$ and $E_{1}=6.37$ for $B$-estimates which are in satisfactory argeement with one another and with the evidence of Mather and Philip (Mather, I949a). These estimates can be used to construct expectations for the mean variances of the various generations in table 5 .

The comparison of observed and expected values is perhaps clearer from fig. 8 than from the table. In $A$ the tendency seems to be for the observed value to exceed the expected at first and to fall below it in the middle generations, again approaching and even surpassing expectation at the end. The comparison of expectation and observation in $B$ is less satisfactory since the fluctuations of observation are greater, but it certainly cannot be taken as contradicting the conclusions to be drawn from $A$.

In view of the relation between mean and variance, to which attention has already been drawn, the slight rise in the grand mean 
at the end of the experiment could lead of itself to some rise in mean variance. An adjustment was made for this effect in considering the unweighted data. $A$ and $B$ were pooled for this purpose, as the analysis of the mean squares of the weighted data has given no reliable indication of disagreement between these groups.

The mean variance for each line in each year was divided by the square of the corresponding mean before averaging over lines. This should go a long way towards removing the metrical bias to be expected in the mean variances. The analysis then proceeded along the same lines as with the weighted, but unadjusted, data described above. The adjustment for metrical bias had the effect of lessening the departure of observation from expectation; but even so a departure of the kind found earlier was still in evidence. The value found for $D+\frac{1}{2} H$ by taking the adjusted figure obtained from this analysis and multiplying by the square of the mean of all family means was
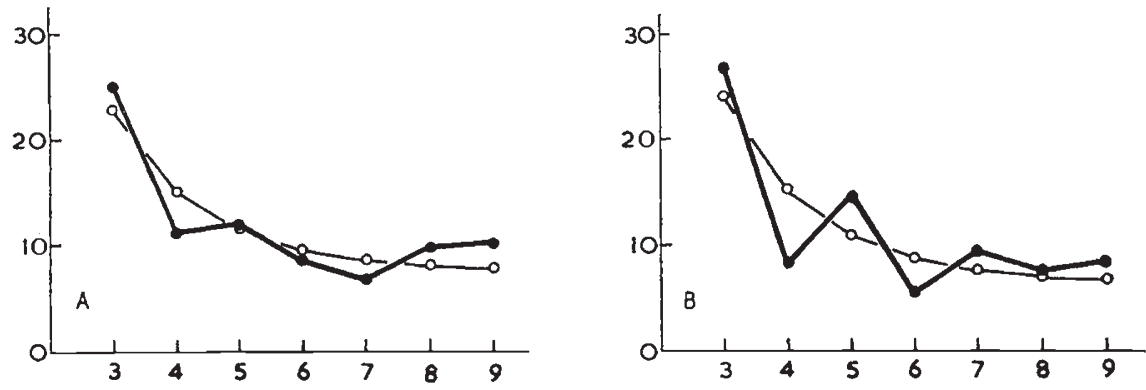

Fig. 8.-Mean Variance (weighted data). Heavy line with black circles, observed values; thin line with open circles, expectation.

$60 \cdot 44$. This agrees quite well with the figures from the earlier analysis. $E_{1}$ was similarly found as $6 \cdot 24$.

Whether a fully adequate adjustment of the scale would have removed all the departure is impossible to say. One fact suggests that it would not. The analyses described were made on the data from generations $F_{3}-F_{9}$ : the variance of $F_{2}$ was not included in either of the above analyses because of the small number of plants available. The value observed for variance of $F_{2}$ was $58 \cdot 29$, as compared with $25^{\circ} 44$ for mean variance of $F_{3}$. In so far as the $F_{2}$ figure is trustworthy it would indicate a too rapid fall between $F_{2}$ and $\mathrm{F}_{3}$. This departure is, of course, of the kind we have already discovered, and in the case of the $F_{2}-F_{3}$ fall it is unlikely to be due to metrical bias, for the difference between the means of the two generations is very small.

It is worthy of note that taking $E_{1}$ as $7 \cdot 0$, i.e. an approximate value lying between the estimates obtained from the weighted and unweighted analyses, $\frac{1}{2} D+\frac{1}{4} H$ of $\mathrm{F}_{2}$ is $5 \mathrm{I} \cdot 29$ while $\frac{1}{4} D$ and $\frac{1}{8} H$ from $F_{3}$ is 18.44 (unweighted figures). Thus there has been a fall of 
$\underline{(51 \cdot 29-36 \cdot 88) 100}$ $5^{\mathrm{I}} \cdot 29=26$ per cent. in the value of $D+\frac{1}{2} H$ from $\mathrm{F}_{2}$ to $\mathrm{F}_{3}$.

This is in close agreement with the fall ratio of 27 per cent. found by Mather and Philip for the compound ear character that they used. We are therefore encouraged to believe that the departure of the series of mean variances from the simple mendelian expectation is due to something more deep-seated than mere metrical bias. In so far as the departure is reliable it would indicate coupling linkage or selection favouring homozygotes. Mather and Philip ascribed the corresponding change that they observed to coupling linkage.

The covariance of individual parent value with mean of offspring contains no non-heritable $(E)$ component. Since no separation was made into lines in this analysis the expectation of the covariance for each generation is the sum of the two items in columns (iv) and (v) of table I. It will be seen that this expectation contains $D$ and $H$ components whose relative proportions change with generations. The progress of the changes in covariance is thus not independent of the degree of dominance. Two analyses have therefore been undertaken of the covariances weighted to compensate for the loss of lines by infertility. One analysis assumes the absence or balance of dominance for all genes $(H=0)$, and the other assumes an average of complete, but not excessive, dominance $(H=D)$. Assuming $H=0, D$ is estimated, from the sum of the covariances of all seven generations tested, as 90.97 in series $A$ and 75.13 in series $B$. With dominance

TABLE 6

Covariance of parent $\left(\mathrm{F}_{n-1}\right)$ and progeny $\left(\mathrm{F}_{n}\right)$ (weighted data)

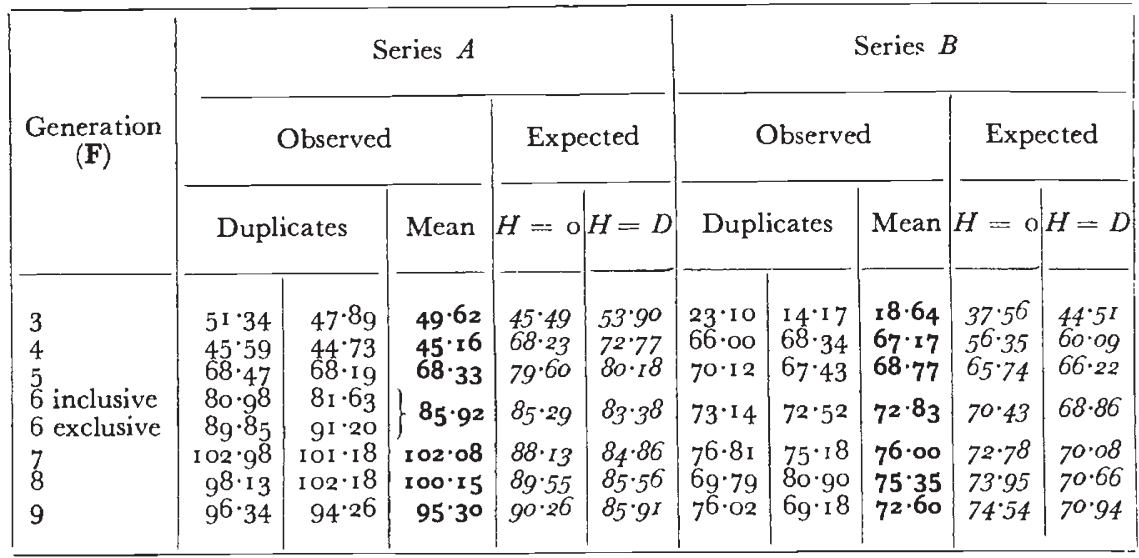

the estimate is $D=H=86.24$ in $A$ and 71.22 in $B$. The values expected for the covariances of each generation on the basis of uncomplicated mendelian inheritance can then be found by substitution for $D$ and $H$ in the standard formulæ (table 6). 
The covariances observed and expected with and without dominance are compared for series $A$ and $B$ in fig. 9. It will be seen that the difference between the expectations obtained assuming $H=0$ and $H=D$ is so small as compared with the difference between observation and expectation that dominance cannot be regarded as having an effect of any importance on our interpretation of the results. In general the observed values are lower than those expected in the early generations and higher than in the later ones. There is a general similarity between series $A$ and $B$, though the agreement between expectation and observation is much closer in $B$ than in $A$. The departures from expectation in both lines are the opposite of those seen in the mean variances, being such as would indicate either repulsion linkage or selection favouring heterozygotes. It is, however, very doubtful whether the departures in $B$ can be regarded as having
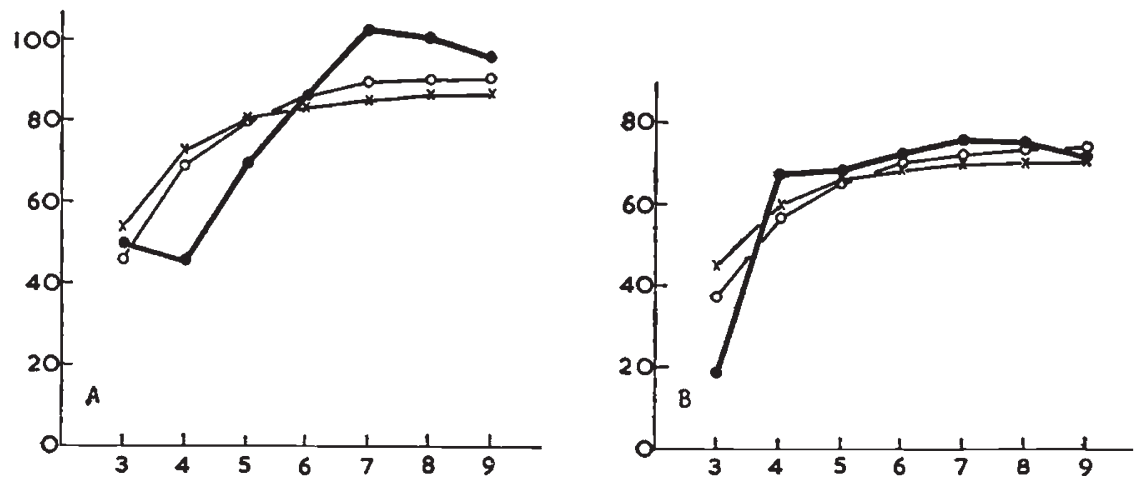

Fic. 9.-Covariance of Parent and Progeny (weighted data). Heavy line, observed values; thin lines, expectation with $H=0$ (open circles) and $H=D$ (crosses).

any significance. Those in $A$ are more definite in indicating repulsion linkage or selection for heterozygotes, since the graph of observed covariances even crosses that of the expected between generations 5 and 6 as would then be anticipated (see fig. 4). We shall examine the nature of the departure more closely below.

The variances of family means give information very similar to that from the covariances, and their changes must indeed be highly correlated with those of the covariances. No great additional weight can therefore be given to any conclusions in which the variances of means support the covariances.

The variances of means contain, in addition to $D$ and $H$ components, an item $E_{2}$ which measures the non-heritable variation of family means. As with $E_{1}$, it will be assumed that $E_{2}$ was constant over generations. It will also be assumed that $H=0$. We have already seen that dominance has little effect on the interpretation of the covariances and its effect will be even less on that of the variances of means, for the $H$ component of these is always half that of the 
covariances. The assumption of absence of dominance also has the effect of lightening the calculations.

Assuming $H=0$, the sum of all seven variances of means in either line (weighted for loss due to infertility) will exceed the sum of the seven covariances by $7 E_{2}$. Then assuming $D=90.97$ and $75 \cdot 13$ as

TABLE 7

Variance of means (weighted data)

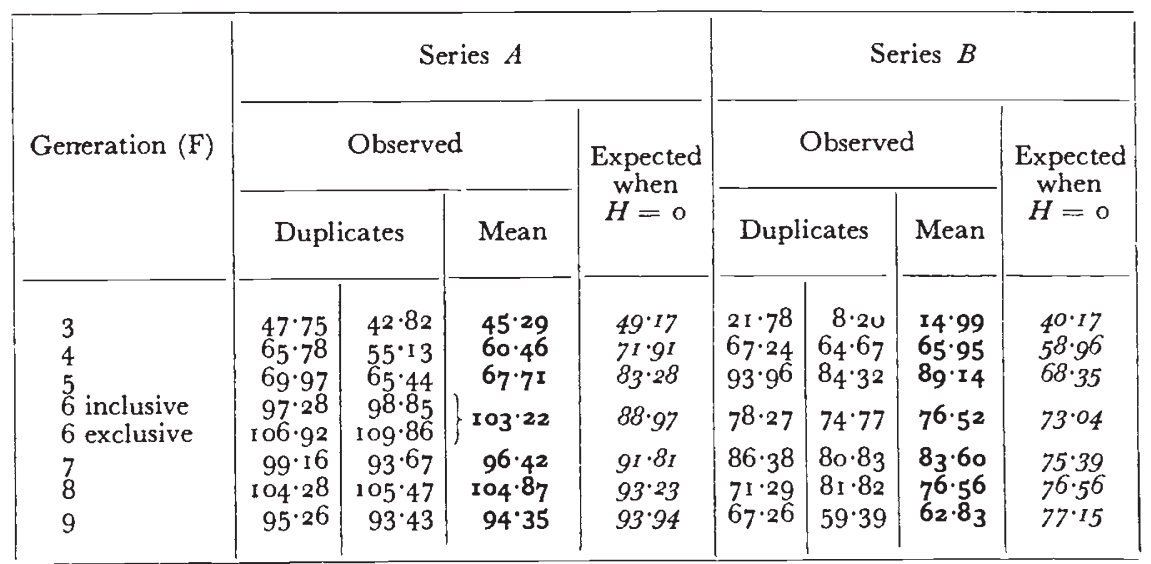

found from the covariances for series $A$ and $B$ respectively, $E_{2}$ will be estimated as 3.68 in $A$ and $2 \cdot 6 \mathrm{I}$ in $B$. These estimates are in reasonable accord with those found for $E_{1}$ from the mean variances
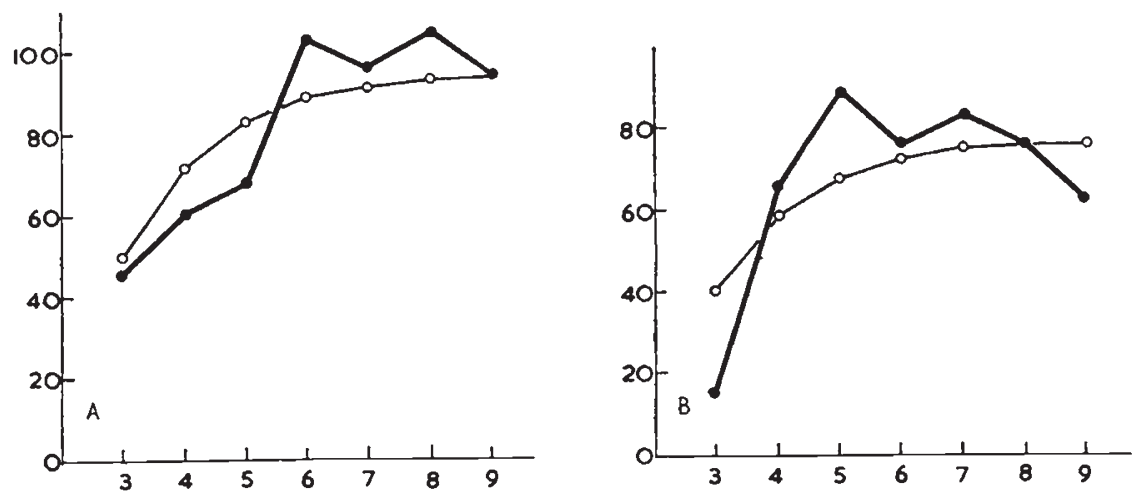

FIG. 10.-Variance of Means (weighted data). Heavy line, observed values ; thin line with open circles, expectation when $H=0$.

and also with the direct estimate of $E_{2}$ found earlier. Then substituting for $D$ and $E_{2}$ the expected values for the different generation are found as shown in table 7. They are compared with observation in fig. Io.

As would be expected, fig. Io agrees quite well with fig. 9 which sets out the covariance results. The agreement of expectation and observation in series $B$ is less good than in the covariances, but since 
the main difference is due to the fall observed in the variance of means from $F_{7}$ to $F_{9}$, no great weight can be attached to it : it must be largely due either to vagaries of sampling or to non-genetic causes. Furthermore, this difference between the indications from the covariances and variances of means is sufficiently large for it to suggest that the apparent contradiction between the mean variances and covariances should not be regarded as having any serious genetical implications.

The behaviour of the covariance and variance of means has been examined further using the figures unweighted for loss of families arising from infertility. In this analysis series $A$ and $B$ are broken down each into its constituent lines (table 8 ). Since the covariance

TABLE 8

The mean of the variance of $F_{n}$ means and covariance of $F_{n-1}$ parents and $F_{n}$ progenies, within and between lines (unweighted data)

\begin{tabular}{|c|c|c|c|c|c|c|c|c|}
\hline \multicolumn{2}{|c|}{$n$} & 3 & 4 & 5 & 6 & 7 & 8 & 9 \\
\hline \multirow[t]{2}{*}{$\begin{array}{l}\text { Within } \\
\text { Lines }\end{array}$} & $\begin{array}{ll}\text { A } & 4 \\
\text { A } & 5 \\
\text { A } & 8 \\
\text { A } & 9 \\
\text { Ar } \\
\text { B } & \text { I } \\
\text { B } & 5\end{array}$ & $\begin{array}{l}\ldots \\
\ldots \\
\cdots \\
\ldots \\
\cdots \\
\cdots \\
\ldots\end{array}$ & $\begin{array}{r}\mathrm{I} \cdot 60 \\
\mathrm{I} \cdot 79 \\
4 \cdot 34 \\
\mathrm{I} \cdot 48 \\
\mathrm{I} \cdot 65 \\
50.25 \\
10 \cdot 64\end{array}$ & $\begin{array}{r}0.91 \\
14 \cdot 76 \\
3 \cdot 42 \\
0 \cdot 45 \\
19 \cdot 24 \\
48 \cdot 11 \\
11 \cdot 12\end{array}$ & $\begin{array}{r}\mathrm{I} \cdot 0 \mathrm{I} \\
10.72 \\
10.28 \\
9.74 \\
44.92 \\
37.74 \\
17.51\end{array}$ & $\begin{array}{c}0 \cdot \text { I I } \\
0.90 \\
8 \cdot 51 \\
14.34 \\
3.05 \\
41.92 \\
22.58\end{array}$ & $\begin{array}{r}0.84 \\
0.86 \\
9 \cdot 46 \\
20 \cdot 80 \\
2.98 \\
46 \cdot 92 \\
18.04\end{array}$ & $\begin{array}{r}0.21 \\
1 \cdot 84 \\
11 \cdot 92 \\
27 \cdot 82 \\
6 \cdot 80 \\
41 \cdot 27 \\
18 \cdot 62\end{array}$ \\
\hline & Mean & ... & $x+82$ & $14 \cdot 00$ & $18 \cdot 85$ & 13.06 & $14 \cdot 27$ & 15.49 \\
\hline \multicolumn{2}{|c|}{ Between Lines } & $39 \cdot 19$ & $50 \cdot 8 x$ & $66 \cdot 65$ & $79 \cdot 34$ & $100 \cdot 60$ & $101 \cdot 54$ & $95 \cdot 4^{8}$ \\
\hline
\end{tabular}

* The sudden fall from the previous generation in these lines is due to the loss of all families with low means.

and the variance of means are so highly correlated they have been averaged for each generation, and the average used in the analysis.

The covariance (and variance of means) calculated between lines, i.e. found as the covariance of line means in successive generations (statistics (iii) and (iv) see table I), should be virtually constant. The coefficient of $H$ is reduced to a quarter by each generation but that of $D$ is constant at $\frac{1}{2}$. When we come to examine the results, however, we find that the covariance and variance of means are both rising. They average $39 \cdot 19$ for $F_{2}-F_{3}$, rising to $50 \cdot 8 \mathrm{I}$ for $F_{3}-F_{4}$ and reach a peak of IOI 54 in $F_{7}-F_{8}$. This must be a reflection of the selection against intermediate phenotypes which we have already observed to be causing the line means to diverge in the later generations. Indeed, the rising covariance and variance of means are themselves clear evidence of such divergence.

The covariance and variance of means within lines, and averaged over lines (statistics (iii) and (v) in table I) rises more slowly (table 8). 
The rise is indeed irregular, there being a sharp peak at $F_{5}-F_{6}$. This is largely due to the irregular behaviour of lines $A_{5}$ and $A_{10}$ which both show a sharp fall between that generation and the next, due to death of low-meaned families in each line. If these lines are eliminated the results are less irregular, but even so there is a fall where the greatest rise is expected, between the $\mathrm{F}_{3}-\mathrm{F}_{4}$ and the $\mathrm{F}_{4}-\mathrm{F}_{5}$ figures. Thereafter the combined statistic follows much the expected course, perhaps with a tendency to rise too slowly in the way that would follow from repulsion linkage or selection for heterozygotes, herein imitating the much greater deviation of the between-lines statistics (table 9 and fig. I I).

TABLE 9

Mean of covariance of parent and progeny and variance of mean within lines (unweighted data and omitting lines $\mathrm{A}_{5}$ and $\mathrm{A}_{\mathrm{o}}$ )

\begin{tabular}{|c|c|c|c|c|}
\hline \multirow{2}{*}{$F$} & \multirow{2}{*}{ Composition } & \multirow{2}{*}{ Observed } & \multicolumn{2}{|c|}{ Expected } \\
\hline & & & $H=\mathrm{o}$ & $H=D$ \\
\hline 4 & $\frac{1}{4} D+\quad \frac{3}{64} H+\frac{\mathrm{I}}{2} E_{2}$ & $\times 3.66$ & $10 \cdot 6 \mathrm{I}$ & I I 75 \\
\hline 5 & $\frac{3}{8} D+\frac{9}{256} H+\frac{1}{2} E_{2}$ & $12 \cdot 80$ & 14.92 & $15 \cdot 4^{8}$ \\
\hline 6 & $\frac{7}{16} D+\frac{21}{1024} H+\frac{1}{2} E_{2}$ & $15 \cdot 26$ & I $7 \cdot 08$ & 17.05 \\
\hline 7 & $\frac{15}{3^{2}} D+\frac{45}{4096} H+\frac{1}{2} E_{2}$ & $\times 7 \cdot 49$ & I $8 \cdot 16$ & 17.77 \\
\hline 8 & $\frac{3 \mathrm{I}}{64} D+\frac{93}{\mathrm{I} 63^{8} 8_{4}} H+{ }_{2}^{\mathrm{I}} E_{2}$ & $x 9.21$ & $18 \cdot 70$ & I $8 \cdot I_{1}$ \\
\hline 9 & $\frac{63}{128} D+\frac{189}{65536} H+\frac{1}{2} E_{2}$ & 19.97 & I 8.97 & $18 \cdot 27$ \\
\hline
\end{tabular}

The expectations are based on $E_{2}=3.95$ (estimated by comparison of Covariance and Variance of Mean), $D=34^{.51}$ (when $H=0$ ) and $D=3^{2} \cdot 9^{1}$ (when $H=D$ ) estimated by least squares. The expectations are not sukstantially altered when $E_{2}=2 \cdot 7^{8}$ as found by the direct comparison described earlier.

Any such slight departure of the course of the series of covariances, etc., within lines is, however, small as compared with the effects of the rise in the covariance between lines, especially as there are chance irregularities in it. It is this which caused the major confusion in the weighted analyses. The apparent evidence for repulsion linkage or selection for heterozygotes should not therefore be taken seriously. Another comparison indeed suggests the kind of effect we have already encountered in the mean variances. The minimal value for the average of covariance and variance of means between lines is 39 in $\mathrm{F}_{2}-\mathrm{F}_{3}$ (table 8). This will be a reasonably unbiased estimate of $\frac{1}{2} D+\frac{3}{32} H$ in that generation, as the non-heritable component will be $\frac{E_{2}}{2}$ Thus $D$ must be in the neighbourhood of 78 , or perhaps a little higher, 
in that generation. The covariance between lines would give a higher value for $D$ in later generations. The covariance, etc., within lines, on the other hand, gives an average of about 35 for $D$ in the generations after $F_{2}-F_{3}$. Thus, on this evidence, $D$ has fallen in the way that would arise from coupling linkage or selection for homozygotes.

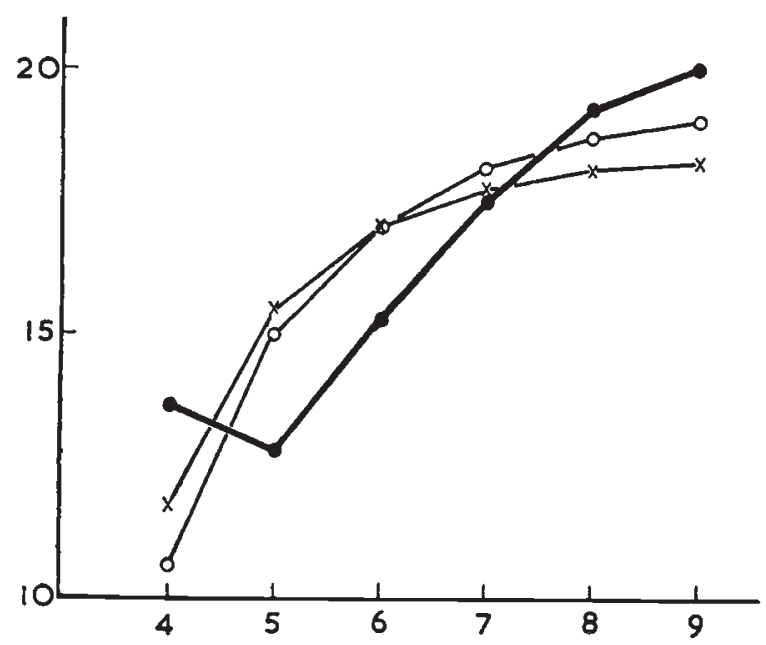

FIG. I1.-Mean of Covariance and Variance of Means within lines, excluding $A_{5}$ and Aro (unweighted data). Thick line, observed values; thin lines expectation with $H=0$ (open circles) and $H=D$ (crosses).

Table Io shows the changes in the correlation coefficient of parents and offspring over the generations in each series. The correlation coefficient for $\mathrm{F}_{n}$ is found as $\frac{\mathrm{W}_{n}}{\left(\mathrm{~V}_{n-1}-\mathrm{V}_{n}\right)^{\frac{1}{2}}}$, where $\mathrm{W}_{n}$ and $\mathrm{V}_{n}$ are the covariance and variance of means respectively in that generation,

TABLE Io

Correlation of parent $\left(\mathrm{F}_{n-1}\right)$ and offspring $\left(\mathrm{F}_{n}\right)$

\begin{tabular}{|c|c|c|c|c|c|c|}
\hline \multirow{2}{*}{ F } & \multicolumn{3}{|c|}{ Series $A$} & \multicolumn{3}{|c|}{ Series $B$} \\
\hline & \multicolumn{2}{|c|}{ Duplicates } & Mean & \multicolumn{2}{|c|}{ Duplicates } & Mean \\
\hline 3 & 0.89 & 0.89 & 0.89 & & & $\ldots$ \\
\hline 4 & 0.87 & 0.94 & $0.9 x$ & 0.90 & 0.95 & 0.92 \\
\hline $\begin{array}{l}5 \\
6 \text { inclusive }\end{array}$ & 0.91 & 0.93 & 0.92 & 0.92 & 0.94 & 0.93 \\
\hline $\begin{array}{l}0 \text { inclusive } \\
6 \text { exclusive }\end{array}$ & $\begin{array}{l}0.94 \\
0.95\end{array}$ & $\begin{array}{l}0.94 \\
0.95\end{array}$ & 0.94 & 0.94 & 0.95 & 0.94 \\
\hline $\begin{array}{l}7 \\
8\end{array}$ & $\begin{array}{l}0.95 \\
0.95\end{array}$ & $\begin{array}{l}.93 \\
\text { o.96 } \\
\text { o.98 }\end{array}$ & $\begin{array}{l}0.96 \\
0.97\end{array}$ & 0.95 & 0.96 & 0.95 \\
\hline 9 & 0.94 & 0.93 & 0.94 & 0.92 & 0.90 & 0.91 \\
\hline
\end{tabular}

and $\mathrm{V}_{n-1}$ the variance of means in the previous or parental generation. Now apart from $E_{2}, \mathrm{~W}_{n}$ must closely approximate to $\mathrm{V}_{n}$ as the $D$ components are identical and the $H$ are small. Furthermore, $\mathrm{V}_{n-1}$ 
differs from $\mathrm{V}_{n}$ only by $\left(\frac{1}{2}\right)^{n-2}$ in $D$ and not at all in $E_{2}$. We should thus expect to find only small changes in the correlation coefficient, changes which will reflect only feebly the rise of the heritable component of variation in $\mathrm{V}$ and $\mathrm{W}$ relative to the non-heritable component. The coefficients observed fully substantiate this expectation. As will be seen from table $\mathrm{r} 0$, the correlation coefficient is uninformative.

Viewing the experiment as a whole, it shows a fair consistency in most respects. The values of $E_{1}$ found from the mean variances of the two lines in the weighted data agree well enough with one another, as do the values of $E_{2}$ found directly and from the covariances and variances of means. Furthermore, $E_{1}$ and $E_{2}$ show a reasonable relation with one another.

Table I I shows the estimates of $D+\frac{1}{2} H$ obtained from the various sources in both weighted and unweighted data. Series $B$ seems to have been, by chance, little if any less variable than its ancestor

TABLE II

Comparison of the estimates of the components of variation $\left(D+\frac{1}{2} H\right)$

from various sources

Weighted data

\begin{tabular}{|c|c|c|c|}
\hline \multirow{2}{*}{ Series } & \multirow{2}{*}{$\begin{array}{c}\text { Mean Variance } \\
\left(\mathrm{F}_{3}-\mathrm{F}_{9}\right)\end{array}$} & \multicolumn{2}{|c|}{ Covariance $\left(\mathrm{F}_{2 / \mathrm{s}}-\mathrm{F}_{\mathrm{g} / \mathrm{g}}\right)$} \\
\hline & & $H=\mathrm{o}$ & $H=D$ \\
\hline $\begin{array}{l}A \\
B\end{array}$ & $\begin{array}{l}6 \mathrm{I} \\
7 \mathrm{I}\end{array}$ & $\begin{array}{l}91 \\
75\end{array}$ & $\begin{array}{l}129 \\
107\end{array}$ \\
\hline
\end{tabular}

Unweighted data (both series pooled)

\begin{tabular}{|c|c|c|c|c|c|}
\hline \multicolumn{2}{|c|}{$\begin{array}{c}\text { Overall } \\
\text { Mean Variance }\end{array}$} & \multicolumn{4}{|c|}{$\begin{array}{c}\text { Covariance and Variance of Means } \\
\text { (joint estimate) }\end{array}$} \\
\hline \multirow{2}{*}{$\mathrm{F}_{2}$} & \multirow{2}{*}{$\mathrm{F}_{3}-\mathrm{F}_{9}$} & \multicolumn{2}{|c|}{ Between Lines $\left(F_{2 / 3}\right)$} & \multicolumn{2}{|c|}{ Within Lines $\left(\mathrm{F}_{\mathrm{s} / 4}-\mathrm{F}_{\mathrm{g} / \mathrm{9}}\right.$} \\
\hline & & $H=\mathrm{o}$ & $H=D$ & $H=\mathrm{o}$ & $H=D$ \\
\hline ca 100 & 60 & 78 & 94 & 35 & 59 \\
\hline
\end{tabular}

series $A$. It is thus legitimate to pool the two. It will be seen that whether the estimate comes from mean variance or covariance and variance of means, it is always higher when the $F_{2}$ variance, or its equivalent, the $\mathrm{F}_{2}-\mathrm{F}_{3}$ covariance and $\mathrm{F}_{3}$ variance of means, is taken as, or included in, the source, than when estimation is solely from the later generations.

With uncomplicated inheritance the various estimates should agree apart from sampling variation; but a difference of the kind found 
is to be expected with either coupling linkage or selection favouring homozygotes. With coupling linkage the values of $D$ and $H$ (as opposed to their coefficients) diminish steadily with the generations, the greatest fall being from $F_{2}$ to $F_{3}$ (Mather, $1949 a$ ). A corresponding effect follows when selection favours homozygotes. The coefficients of $D$ and $H$ (as opposed to their actual values) will then fall much more sharply than would be the case in the absence of selection. Then assuming the unselective coefficients of $D$ and $H$, as we have done in these analyses, the estimates of $D+\frac{1}{2} H$ will fall with the generations.

This fall is directly observable from the analysis of the unweighted data in table I I where the estimates from $\mathrm{F}_{2}$ and from later generations are separated; it being borne in mind, of course, that the $F_{2}-F_{3}$ covariance and the $\mathrm{F}_{3}$ variance of means depend on the same $D$ and $H$ components as does the variance of $F_{2}$. In the weighted data the fall with generations is not shown directly but is nevertheless clear. For the estimate from the mean variance will depend on the values of $D$ and $H$ in generations $\mathrm{F}_{3}$ onwards, whereas the chief items in the overall covariance must arise from the $D$ and $H$ of $\mathrm{F}_{2}$ which makes the chief contribution to the overall covariance in all generations. The higher estimate of $D+\frac{1}{2} H$ from the overall covariance as compared with mean variance thus reveals the greater values of $D$ and $H$ in $\mathrm{F}_{2}$ than in later generations.

Considering next the unweighted data, the value of $D+\frac{1}{2} H$ found from $F_{2}$ mean variance is based on but few degrees of freedom and so cannot be regarded as highly reliable. The corresponding estimate from the covariance and variance of means is based on no more degrees of freedom but includes data from the next generations. The general agreement between the mean variances and the other statistics must thus be our chief source of confidence in the trustworthiness of the comparisons and the reliability of the conclusions.

There is thus good overall evidence for the supposition that coupling linkage or selection in favour of homozygotes is operating in the experiment. It may be noted too, that Mather and Philip (ibid.) record evidence for coupling linkage in this barley cross, the possibility of selection not being considered. Certainly the results cannot be taken as indicating any great favouring of heterozygotes by selection, such as seems to be found in many species like maize, pigs or poultry, which, we observe, differ from barley also in their natural breeding systems, being out-breeding as opposed to inbreeding.

No analytical means exists at present for using the data of this experiment to decide between the alternatives of coupling linkage and selection favouring homozygotes. No observation has, however, been recorded which would suggest that homozygotes as such are more vigorous or fertile than individuals homozygous for fewer genes in barley, though we have evidence that selection has acted against intermediate phenotypes. It seems unlikely, therefore, that selection 
is the explanation of the fall in the components of variation with the generations. Linkage preponderantly in the coupling phase is the more attractive explanation, with little, if any selective differential between the more homozygous and the more heterozygous. The progress of inbreeding, i.e. the rise of homozygosis, seems to have followed much the course that would be expected on simple mendelian grounds.

Before leaving this barley experiment it will perhaps be useful to draw specific attention to its three chief defects. The first is that it started with very few $\mathrm{F}_{2}$ plants (or $\mathrm{F}_{3}$ plants in series $B$ ) : the initial sampling variation, therefore, may well have been unduly high. Secondly, as we have already observed, the duplication in the experiment was not such as would provide a valid estimate of error variation. Thirdly, no means was available of independently detecting any changes in the value of $E_{1}$ from year to year. In designing future experiments for the measurements of progress in homozygosis under inbreeding, it would be desirable to commence with a bigger population of $\mathrm{F}_{2}$ individuals, say 20 as a minimum; to arrange the internal duplication of the experiment in such a way that it would yield a measure of the total sampling variation, that of parents as well as of progeny; and to include every year the true breeding parent lines at least, so as to provide annually a direct estimate of $E_{1}$ and $E_{2}$ and thereby to detect any major changes that they might show and that might affect the comparisons upon which judgment of the progress of inbreeding must depend.

\section{SUMMARY}

The rise of homozygosis under a system of inbreeding will be affected by selection, natural or artificial. It will be slowed down by selection in favour of heterozygotes, and in an extreme case may be prevented altogether. Expected frequencies of homozygosis, calculated on the assumption of inheritance uncomplicated by selection, will not therefore be realised in species where selection is operative. It is to be expected that selection will favour heterozygotes in species, whether plant or animal, which reproduce by outbreeding. It will be of lesser effect, and perhaps absent, in species (such as barley) which normally inbreed.

The biometrical analysis of continuous variation affords an experimental method of studying the progress of inbreeding and the action of selection on it. The different variances and covariances measuring variability in the various generations can be expressed in terms of the quantities $D, H$ and $E$ (Mather, I949 $a$ and $b$ ). The coefficients of $D$ and $H$ vary with the system of breeding, and are also affected by selection in favour of heterozygotes or homozygotes. $D$ and $H$ themselves may change in value if breakable linkage is operative. Thus, in theory, linkage and selection have difierent effects, but, in practice, selection favouring heterozygotes may be 
difficult to distinguish from repulsion linkage, and selection favouring homozygotes from coupling linkage.

An experiment with ear size in barley is described in which, following a varietal cross, self-pollination was practised up to $F_{q}$. There is some direct evidence of the action of natural selection in the experiment, but it was selection against intermediate phenotypes rather than against heterozygotes or homozygotes. There is also evidence that the scale of measurement of ear internode length was not fully adequate, in that non-heritable variance was correlated with mean measurement. These two disturbances cause certain complications in the analysis and interpretation of the results.

In the absence of selection and linkage the heritable portion of the mean variance of families should be halved in each generation. The series observed suggests that the decline is, in fact, at first more rapid than this. Such a result suggests, either selection for homozygotes, or coupling linkage. The series of parent offspring covariances and variances of family means at first suggests the opposite. Much of this appearance arises from the selection against intermediate phenotypes and, in fact, these statistics cannot be regarded as disagreeing with the mean variances.

When analysed, assuming coefficients uncomplicated by selection, both mean variances, on the one hand, and covariances and variances of means on the other, give values of $D$ and $H$ which are higher in $F_{2}$ and $F_{3}$ than in later generations. This effect would follow either selection for homozygotes or coupling linkage. It is considered that coupling linkage is the more likely explanation. Certainly there can be no selection favouring heterozygotes, such as would be expected in outbreeding species, though not in barley and other inbreeders.

The parent offspring correlation coefficient is shown to be an uninformative statistic. Certain weaknesses in the design of this experiment are discussed and suggestions made for improvement in future experiments.

\section{REFERENCES}

BARTLETT, M. S., AND HALDANe, J. B. S. 1934. The theory of inbreeding in autotetraploids. F. Genet., 29, 175-180.

DÜzGüNEs, O. 1950. The effect of inbreeding on reproductive fitness of S.C.W. Leghorns. Poultry Science, 29, 227-235.

FISHER, R. A. 1949. The Theory of Inbreeding. Edinburgh : Oliver and Boyd. HALDANE, J. B. S., AND WADDington, c. H. 1931. Inbreeding and linkage. Genetics, $16,357-374$.

JENNINGS, H. S. 1916. The numerical results of diverse systems of breeding. Genetics, I, 53-89.

MATHER, K. I 949 a. Biometrical Genetics. London : Methuen.

mather, K. 1949b. The genetical theory of continuous variation. Proc. 8th Int. Cong. Genetics (Hereditas Suppl. Vol.), 376-401.

MATHER, K., AND HARRISON, B. J. 1949. The manifold effect of selection. Heredity, $3,1-52$ and $131-162$. 